\title{
The Importance of Scientific Education in the Primary School
}

\author{
Phd Candidate,Doc.Aranit Gjipali
}

\author{
University of Vlore "Ismail Qemali"
}

Phd Candidate.llva Lamaj

Doi:10.5901/jesr.2014.v4n4p357

University of Vlore "Ismail Qemali"

\section{Abstract}

\begin{abstract}
This topic is chosen to analyse the central role that schools can play in childhood training of complex thought of the child. In contrast to a traditional, static and conservative model of education, there arises the need for a theming of thinking in education as a condition for overcoming the partiality of the reductionism for the overcoming o pedagogical logic who forgets that education is not only to instruct but care and integral growth of the person too. We have based our work on the reflective thinking by J. Dewey and complex thought with its components (critical, caring, creative ) we want to emphasize the importance of science education already in kindergarten as a means to achieve this result. Science education provides an opportunity to undertake early learning paths in science, without previews, the recognition of the ability to implement appropriate strategies for thinking in a positive atmosphere of observation, exploration, research, dialogue, development and verification forecast, anticipation of hypotheses, the use of a specific vocabulary for the description and reflection, reasoning consequent to argue and explain events. Such education may be required for the formation of an individual's own responsibility , is important to help people to be the protagonists of their own cognitive processes and to think critically. Through the observations carried out in two primary schools of the city of Vlore there was evidence of what limits are still present in these classroom settings, still tied to educational models characterized by reductionism, the fragmentation of knowledge, from stereotyping. What we wanted to highlight was the importance of critical thought in this age and the role of the teacher in motivating children not just repeating or learning but thinking and create.
\end{abstract}

\section{Introduction}

One of the most important components of our civility is the so called rationalist tradition, inherited by the ancient Greeks. This is the tradition of the critical discussion related to the search of the truth. It is the moment when science engages itself in creating critical thinking aimed at wiping out a set of biased and old beliefs and at enabling us to accurately think over an argument and make hypotheses. Therefore, science is considered as one of the most liberal and favorable influences on human thinking. Critical thinking is the typical method through which science enables the achievement of an objective and reliable consciousness.

To work on the development of critical thinking in elementary school means to aim at the development of creativity, curiosity, and deductive and hypothetical thinking, which are all part of many multidisciplinary study fields. In our society, school is the most important institution for the reason that it is the means through which any individual gives him/herself a chance to leave a mark on the future. School is a kind of designer for the future society; that is why emphasis is placed on the development of child scientific education and on the development of critical thinking starting from the end of the pre-school age and restarting with the elementary school age. In this way only children will be able to argument any achievement and to face any eventual problematic situation by not falling in prejudice and stereotypes. That is why emphasis is placed on the need to develop child thinking. The most important think about this is not to learn children retell what they listen; rather, it is to teach them how to be responsible for their being.

It is the duty of education and teachers to leave behind traditional education - a system which focuses on the teacher, rather than on the students. This kind of system enables mental passivity rather than critical thinking and lead children to a mental artificiality. Traditional school tends to competitiveness rather than to collaboration, which has been indicated by the recent researches as one of the most constructive ways to child learning.

Often scientific teaching has been inaccurately performed by aiming at the development of a dogmatic thinking, which in no way helps children develop their creativity; rather, it increasingly leads to a centralized teaching, reproduction and inability to inquire.

It is important to develop child critical thinking, as this will contribute to the development of freedom of thought, of 
child authority, and above all, of his/her willingness to explore reality. This work is aimed at highlighting this problem, for the reason that, in our school, teachers still focus on and employ traditional teaching, which consists in reproductive rather than in creative learning. In our schools, it is still present a phenomenon that eliminates the importance of graphic elaboration, information and spontaneous gesture reproduction. In this way children are obliged to constrain their individuality and creativity, and what is more important, they are not allowed to freely reflect, observe, experiment or make hypotheses.

If we refer to the work of John Dewy (1859 - 1952), which highlights the need for intellectual development based on the development of either individual or group cognitive responsibility, it is essential to promote complex, critical and creative scientific thinking, which would enable children to resolve any difficult situation and would lead them toward problem solution based on arguments rather than on current beliefs or stereotypes. The most important thing for teachers is to engage their pupils - through scientific education - in such situations where children would be protagonists in the learning process, which means that children themselves would have to be leaders of this process by not just reading a text and not understanding the message it conveys.

This kind of education demonstrates the goal of each teacher to encourage pupils make questions on previously presented topics, to give arguments on problem solutions, and what is more important, to develop their creativity, which enables children of this age to create intrapersonal relations and understand the outside world.

Teachers and parents make the frequent mistake of presenting an unreal world to their pupils and children by imposing their thoughts and not enabling them to create their own. According to Lipman, critical thinking enables us to think in a reflective way. This work is aimed at drawing the attention of the adults, particularly of the teachers, to the fact that developing child experience must be the fundamental goal of their educational work.

Pupils' formation based on scientific education enables the development of reflective thinking, which helps them lead their curiosity.

\section{The Importance of Critical Thinking}

Children tend to naturally absorb important attitudes and thoughts of adults. Indeed the structure of adult convictions is imposed to the children, who learn to depend on the thoughts of the others. You can either force them to be narrowminded or encourage them to evaluate their authority and reasoning skills. Furthermore, you can motivate them to have various convictions and viewpoints, to doubt on their own or the other's reasoning. If you want an open-minded child, his/her critical thinking should not be left to chance. To think critically means to encourage children learn how to make questions, how to reason and when to employ reasoning.

The best way toward child critical thinking is to convince children that reasoning and reflection lead to success, whereas narrow thinking leads to failure. The most significant thing about child critical thinking development is the willingness to challenge the others' ideas, which is something children and adults, particularly teachers should bear in mind. All teachers should understand that children have their own personality and opinions, which teacher should respect however contradictory they might be. This doesn't mean that there are correct opinions considering the age referred to in the study. Pupils of this age are still in the phase of egocentrism and tend to focus any motivation on themselves. In such case, reasoning, searching the truth and finding the best way to real thinking to the best possible alternative encourage child critical thinking, by not imposing the others' thoughts on them and, at the same time, by motivating them to always search for the truth. Children should get used with the idea that one of the most significant challenges in their life is the approval or denial of their ideas, which is a very important process to form critical thinking. School is certainly the most appropriate environment to form child critical thinking with children guided by a leading rather than an autocratic adult, who guides them toward problem solutions and do not imposes his/her opinions. If children in our schools would be taught on the basis of critical skills and reflective thinking rather than on the basis of the traditional method, we would have criticizing children capable of discussing their own solutions rather than just accepting conclusions. This phenomenon is still present in our schools, where teachers apply traditional teaching methods by failing to consider child reflective thinking and by treating their pupils like a well to be filled with thoughts rather than a spark ready to illuminate.

\section{The Study}

With the aim of understanding the importance of child critical thinking, this work was based on observations made during several lesson classes in two public schools of Vlore city. The pupils included in this study were from 6 to 10 years old, an age that corresponds to the elementary education of Albanian school system. The work was carried out in two different schools for the only reason of observing the difference between teachers. The method employed in this study was the 
free observation and semi-structured interview directed to teachers. This method was aimed at evidencing their opinion about the way they chose to transmit their ideas to their pupils.

The teachers and the achievement of the goals they had set with regard to the learning level was the focus of this observation along with the confidence of teachers in their abilities. The observation showed that in some cases the teachers' insecurity in conveying information influenced on the development of children thinking. It is confirmed that convictions and knowledge of teachers have an impact on the students' scores (Margendoller, 1997; Staub\&Stern,2002). The four selected classes we have observed, presented two distinct aspects; the first corresponds to the convictions of the teachers, whereas the second to the development of children ideas and to their encouraging in challenging the adults' ideas.

\section{An Efficient Teacher is Evaluated as Such on the Basis of His/Her Abilities to Motivate Students}

In this study we have made two hypotheses:

First, do teachers' convictions influence on child critical thinking?

Second, does students' motivation to challenge teacher's ideas influence on critical thinking?

The observation has been carried out for a period of two months; therefore we had to pass a long time with the teachers and the pupils. Our goal was to observe the confidence of teachers in transmitting the information and their own ideas as well as to understand how their convictions influenced on the perception and definition of such ideas. Another goal was to observe if teachers allowed pupils to contradict the teachers' ideas or if they just impose their own opinion on the pupils, who accepted the information and considered the teacher a master of his/her competences.

The study includes also some interviews directed to teachers who answered questions on the teaching methods they employed with regard to traditional teaching or techniques aimed at developing child critical thinking. We made observations in science and social classes so as to observe teaching of different subjects and the influence of these subjects on the way teachers dealt with those subjects and the perception of pupils on those subjects.

\section{Results}

The results of the performed observation are as follows: with regard to the teachers' convictions, we may say that they have an impact on their perception and judgment on the children intelligence as well as on their efficiency as teachers. Teachers who were confident in their skills always managed to integrate pupils in their teaching class by employing various techniques that stimulated collaboration and offered various alternatives to problem solution. Teachers who employed traditional methods considered themselves less skilled and were always afraid of failing to manage the class and to get the pupils absorb the information. Teaching with these teachers was static and directed toward prejudice and stereotyping of various situations. The most important thing for such teachers was to stimulate individual work and competition.

With regard to the students' scores, those who were taught by teachers who motivated them in searching new ideas, who encouraged them to collaborate and confront their ideas, were able to argue in a more correct way as far as problem solution was concerned and were more creative and more confident in their ideas.

High confidence in their efficiency led to constructive teaching, motivation of pupils to challenge the others' ideas and processes-oriented vision.

Low confidence of teachers in their efficiency led to the selection of a traditional teaching style, static vision and situation stereotyping. In this case pupils were treated like beings to be filled with information and nothing more.

The most important thing for this study is the fact that almost more than half of these teachers (from 16 teachers), although pretended to encourage critical thinking, not always managed to put it into practice. Such teachers followed a traditional teaching method, which didn't encourage collaboration and acquisition of a variety of ideas.

\section{Conclusion}

The observation performed in elementary school classes made us arrive at undesirable conclusions with regard to the development of child thinking. In Albanian schools, much is preached on various programs of teaching development and standard implementation; however there are teachers with static teaching visions who still apply the traditional methods and fail to develop thinking processes and to enable pupils create their own ideas by depriving them from developing their own experiences. What these teachers should understand is precisely the importance of a constructive teaching style in motivating students to think critically. These teachers must understand that development of personal creativity in children 
and how they perceive themselves as human beings with ideas to be expressed freely is very important. Exploring the surrounding world helps children be more confident, more independent and more active in the class. A traditional teaching style makes pupils passive, influenced by teachers' judgment. Therefore we should encourage students to be more reflective, to argue, to make good questions and be able to accurately discover the surrounding environment. This is the special importance of critical thinking.

\section{References}

B.Musai,(1999),Psikologji Edukimi,Tirane.

D.Wood,(1988), How children think and learn,Oxford.

A.Pollard,S.Tann(1993), reflective teaching in primary school,London.

J.Dewey,(1993)How we think,Healt,New York.

J.Dewey(1961)Democrazia ed educazione, Nova Italia,Firenze.

L.S.Vygotskij,(1991)Pensiero e linguaggio,Laterza,Bari 